\title{
RENCANA PENERAPAN CYBER-RISK MANAGEMENT MENGGUNAKAN NIST CSF dan COBIT 5
}

\author{
Obrina Candra Briliyant, Rizqi Aulia Ashari
}

\author{
Sekolah Tinggi Sandi Negara, Jalan Raya Haji Usa Nomor 56 Putat Nutug, Ciseeng, Parung, Bogor, \\ 16120 , Indonesia \\ E-mail: obrina@stsn-nci.ac.id
}

\begin{abstract}
The development of information and communication technology (ICT) has created the cyberspace which enables easier information access and information management fastly and accurately. The use of ICTs that is currently increasing makes the security needs of system used also increase, particularly in regards to the risks. In order to address the issue, a good implementation of cyber-risk management is deemed essential. ABC Organization is one of the government instances managing Indonesia's critical infrastructures. ABC maintains XYZ information system, a strategic IS that is utilized to assist leaders in decision making. In this research, a plan to implement cyber-risk management is proposed using NIST CSF and COBIT 5 to manage cyber risks in XYZ IS. This result of this research are 13 high-value risks and 22 moderate-value risks included COBIT 5 enabler process as risk mitigations. From these, 15 action plans to implement cyber-risk management were developed in accordance with oragnization's capabilities and targets. These action plans were then prioritized based on the needs of the organization.
\end{abstract}

Keywords: cyber-risk management, keamanan siber, NIST CSF, COBIT 5

\begin{abstract}
Abstrak
Kemajuan Teknologi Informasi dan Komunikasi (TIK) membentuk ruang siber yang memudahkan akses informasi maupun pengelolaan informasi secara cepat dan akurat. Pemanfaatan TIK yang meningkat saat ini membuat kebutuhan keamanan pada sistem yang digunakan juga meningkat, terutama terhadap risikonya. Untuk mengatasi hal ini, penerapan cyber-risk management yang baik dianggap perlu. Organisasi $\mathrm{ABC}$ merupakan salah instansi pemerintah pengelola infrastruktur kritis Indonesia. $\mathrm{ABC}$ memelihara sistem informasi $\mathrm{XYZ}$, SI strategis yang digunakan untuk membantu pimpinan dalam pengambilan keputusan. Dalam penelitian ini, diusulkan rencana penerapan cyber-risk management menggunakan NIST CSF dan COBIT 5 untuk mengelola risiko-risiko siber pada sistem informasi XYZ. Hasil penelitian berupa 13 risiko bernilai tinggi dan 22 risiko bernilai sedang disertai dengan enabler process COBIT 5 sebagai mitigasi risiko. Dari hasil tersebut kemudian disusun 15 rencana aksi (program kerja) penerapan cyber-risk management sesuai dengan kapabilitas dan target organisasi. Rencana aksi tersebut kemudian diprioritaskan sesuai kepentingan organisasi.
\end{abstract}

Kata kunci: cyber-risk management, keamanan siber, NIST CSF, COBIT 5

\section{Pendahuluan}

Ruang siber merupakan sekumpulan komputer yang terhubung dalam satu jaringan termasuk layanan, sistem komputer, embedded processor, controller, hingga informasi yang disimpan atau ditransmisikan melaluinya [1]. Terbentuknya ruang siber sebagai akibat dari kemajuan TIK memberikan banyak kemudahan bagi penggunanya [2]. Salah satunya adalah kemudahan akses informasi dan pengelolaan informasi secara cepat dan akurat [3]. Kemudahan tersebut berdampak pada pemanfaatan TIK yang semakin meningkat. Semakin meningkatnya pemanfaatan TIK maka kebutuhan terhadap keamanan sistem, database, dan aplikasi juga semakin memingkat, begitu pula dengan risikonya [4]. Risiko yang muncul dapat menyebabkan kerusakan sistem, pencurian informasi, manipulasi informasi atau perangkat istem, dan penyebaran informasi yang 
mengakibatkan propaganda [5]. Oleh karena itu, risiko tersebut perlu dikelola dengan menerapkan cyber-risk management.

Manajemen risiko merupakan bagian dari keamanan siber yang didefinisikan oleh International Telecommunications Union (ITU) [6]. Keamanan siber saat ini ditujukan secara khusus terhadap instansi pemerintah pengelola infrastruktur kritis seperti pertahanan keamanan, energi, transportasi, sistem keuangan, dan layanan publik lainnya [7]. Hal tersebut dapat dilihat berdasarkan laporan Kementerian Komunikasi dan Informatika (Kominfo) pada tahun 2015 yang menyatakan bahwa sebagian besar dari 28.430.843 serangan siber terjadi pada website pemerintah dengan domain .go.id [8].

Organisasi ABC merupakan salah satu instansi pemerintah pengelola infratsruktur kritis di Indonesia. Organisasi ABC melaksanakan fungsinya melalui Unit Organisasi (UO) ABC berdasarkan peraturan internal organisasi yang dimiliki [7][9]. UO ABC bertugas melakukan pemeliharaan sistem informasi XYZ yang merupakan sistem informasi strategis bagi organisasi [10][11]. Berdasarkan hal tersebut, pada penelitian ini dilakukan penyusunan rencana penerapan cyber-risk management menggunakan NIST CSF dan COBIT 5 untuk mengurangi dan mengelola risiko siber sistem informasi XYZ. NIST CSF digunakan sebagai kerangka kerja yang akan diterapkan dan COBIT 5 sebagai kerangka kerja pendukung. Hasil yang akan didapatkan adalah rencana-rencana penerapan (program kerja) yang dapat diterapkan oleh UO ABC untuk mengelola risiko siber sistem informasi XYZ.

\section{Landasan Teori}

\section{Keamanan siber}

International Telecommunications Union (ITU) mendefinisikan bahwa keamanan siber adalah sekumpulan alat, kebijakan, konsep keamanan, usaha perlindungan, pedoman, manajemen risiko, aksi, pelatihan, praktik, jaminan, dan teknologi yang digunakan untuk melindungi ruang siber dan dimaksud berupa perangkat komputer, personil, infrastruktur, aplikasi, layanan, dan sistem telekomunikasi [6]. Keamanan siber berkaitan erat dengan keamanan informasi yang dikatakan bahwa kedua hal tersebut mempunyai tujuan sama, yaitu mempertahankan kerahasiaan, keutuhan dan ketersediaan. Tujuan keamanan siber adalah untuk mempertahankan kerahasiaan, keutuhan, dan ketersediaan baik informasi maupun lingkungan siber dan seluruh aset organisasi yang berkaitan dengan TI [12].

\section{Cyber-risk management}

Risiko siber merupakan risiko yang disebabkan oleh adanya ancaman siber di dalam ruang siber. Ruang siber merupakan sekumpulan komputer yang terhubung dalam satu jaringan termasuk layanan, sistem komputer, embedded processor, controller, hingga informasi yang disimpan atau ditransmisikan melaluinya [1]. Pada umumnya, ancaman siber ditujukan terhadap cyber-system. Cyber-system merupakan suatu sistem yang dibuat dan penggunaannya bergantung pada ruang siber. Adanya cyber-system tersebut menuntut organisasi untuk menyadari kerawanan sistemnya terhadap ancaman siber. Cyber-risk management dapat diartikan sebagai langkah pengelolaan berkelanjutan dalam menghadapi risiko siber dan ketidakpastian agar mampu memaksimalkan pencapaian tujuan organisasi [5].

\section{NIST CSF}

NIST CSF for Improving Critical Infrastructure merupakan kerangka kerja yang dapat digunakan untuk mengarahkan organisasi pada aktivitas keamanan siber dan mempertimbangkan risiko keamanan siber sebagai bagian dari proses manajemennya. Kerangka kerja ini memberikan panduan dan tahapan dalam meningkatkan keamanan siber melalui analisis risiko keamanan siber. Untuk menerapkannya, kerangka kerja ini memerlukan kerangka kerja yang lain karena sifatnya sangat bergantung pada kerangka kerja lain. Kerangka kerja lain yang dapat digunakan adalah COBIT 5, ISO/IEC 27001, NIST SP.800-53 CCS CSC dan ISA 62443 [13].

Bagian utama dalam kerangka kerja ini adalah framework core yang merupakan satu rangkaian aktivitas keamanan siber, outcome yang diinginkan, dan beberapa referensi informatif yang dapat digunakan untuk mencapainya. Framework core terdiri dari 5 fungsi, yaitu identifikasi (identify); perlindungan (protect); deteksi (detect); respon (respond); dan pemulihan (recovery), 22 kategori dan 100 subkategori yang cocok dengan contoh referensi informatifnya. Terdapat 7 tahapan untuk menerapkan framework core, yaitu:

1) Prioritize and scope

Tahapan ini ditujukan untuk mengidentifikasi sasaran misi dan prioritas kebutuhan organisasi.

2) Orient

Tahapan ini ditujukan untuk mengidentifikasi sistem yang terkait dengan pencapaian sasaran misi dan asetnya, ancaman dan kerawanan terhadapnya.

3) Create a current profile

Tahapan ini ditujukan untuk menentukan 
profil organisasi dengan mengindikasi outcome dari kategori atau subkategori yang dicapai.

4) Conduct risk assessment

Tahapan ini ditujukan untuk menganalisis kecenderungan risiko siber dan dampak yang mungkin terjadi terhadap organisasi.

5) Create a target profile

Tahapan ini ditujukan untuk menentukan target profil organisasi berdasarkan hasil penilaian kategori atau subkategori pada profil organisasi. Kategori dan subkategori yang ditentukan mempertimbangkan hasil analisis risiko. Selanjutnya, organisasi dapat memberikan subkategori tambahan untuk mengatasi risiko organisasi yang unik, yang tidak dapat diatasi dengan pilihan subkategori yang ada.

6) Determine, analyze, and prioritize

Tahapan ini ditujukan untuk membandingkan profil dan target profil organisasi sehingga didapatkan gap. Selanjutnya, ditentukan rencana aksi dan proritasnya yang dapat digunakan untuk mengatasi gap yang ada.

7) Implementation action planTahapan ini ditujukan untuk mengimplementasikan rencana aksi yang telah dibuat. Implementasi rencana aksi dapat digunakan untuk mengaswasi praktik keamanan siber organisasi.

\section{COBIT 5}

COBIT 5 merupakan kerangka kerja yang bersifat komprehensif yang digunakan untuk membantu organisasi mencapai tujuan dalam sudut pandang tata kelola dan manajemen bagi organisasi TI [14]. Penelitian ini menggunakan COBIT 5 family framework yang terdiri dari COBIT 5 Goal Cascade, COBIT 5 Process Assessment Model (PAM), COBIT 5 Self-assessment Guide, COBIT 5 for Risk, dan COBIT 5 Enabling Process sebagai kerangka kerja pendukung NIST CSF.

COBIT 5 Goal Cascade merupakan mekanisme untuk menerjemahkan tujuan atau target organisasi sesuai dengan kebutuhan stakeholder secara spesifik yang kemudian ditindaklanjuti dan disesuaikan dengan tujuan TI dan enabler-nya [14]. COBIT 5 PAM merupakan model dua dimensi yang digunakan untuk menilai kapabilitas proses organisasi [15].

COBIT 5 Self-assessment Guide merupakan salah satu bagian dari COBIT 5 Assessment Programme yang menyediakan cara untuk melakukan penilaian kapabilitas proses TI organisasi secara sedehana tanpa harus menyertakan bukti. Organisasi dapat menggunakan cara ini apabila ingin melaksanakan penilaian secara mandiri tanpa harus melibatkan certified assesor [16]. COBIT 5 for Risk merupakan salah satu produk dari COBIT 5 Product Family yang menangani secara khusus risiko pada TI [17]. COBIT 5 Enabling Process berisi petunjuk penggunaan setiap enabler proses. Pada setiap enabler diberikan petunjuk secara detail bagaimana setiap enabler process tersebut digunakan [14]

\section{Metode}

Metodologi penelitian yang digunakan pada penelitian ini disesuaikan dengan tahapan pada dokumen Implementing NIST The Cybersecurity Framework [18] yang memberikan panduan implementasi NIST CSF menggunakan COBIT 5 dengan tahapan seperti pada Gambar 1.

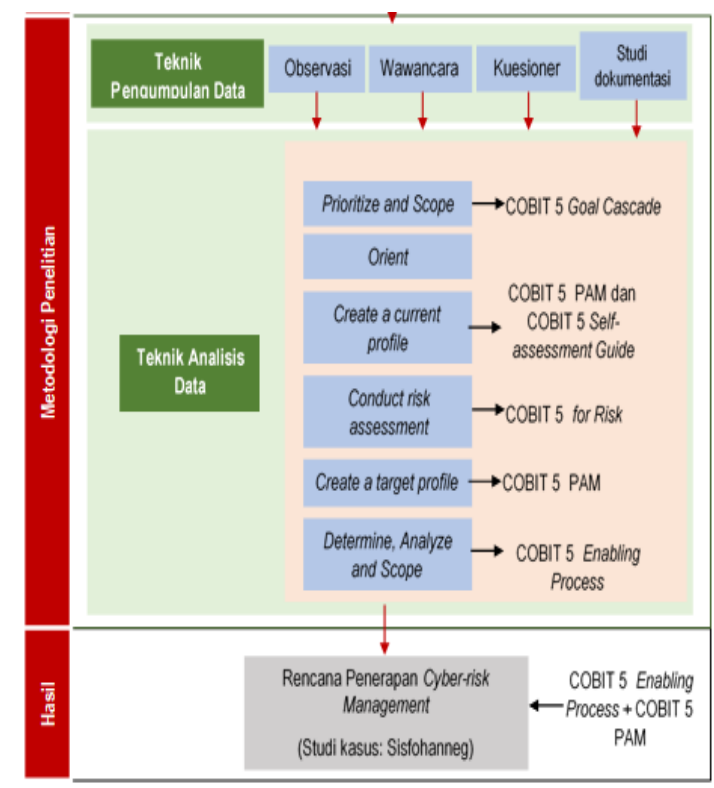

Gambar 1. Metodologi penelitian

\section{Hasil dan Analisa}

\section{Prioritize and scope}

Pada tahap ini dilakukan identifikasi sasaran misi UO ABC dan prioritasnya terhadap sasaran misi yang akan dicapai. Tahapan ini menghasilkan 18 enabler process COBIT 5 yang selaras dengan sistem informasi XYZ sebagai sasaran misi UO ABC. 18 enabler process tersebut kemudian dipetakan dengan NIST CSF sehingga menghasilkan 15 enabler process yang memberikan cybersecurity outcomes pada sistem informasi XYZ. Dari 15 enabler process tersebut, kemudian diprioritaskan 9 enabler process sesuai dengan kebutuhan UO ABC saat ini, yaitu EDM03, APO10, APO12, BAI01, BAI06, DSS01, DSS03, DSS04, dan MEA03. 


\section{Orient dan create a current profile}

Pada tahap ini dilakukan identifikasi aset, ancaman, dan kerawanan terhadap sistem informasi XYZ sekaligus mendefinisikan current profile UO ABC dalam perspektif manajemen risiko. Teridentifikasi 43 aset, 11 ancaman, 23 kontrol keamanan dan 26 kerawanan terhadap sistem informasi XYZ. Selanjutnya dilakukan penilaian kapabilitas UO ABC sebagai current profile menggunakan COBIT 5 PAM dan COBIT 5 Self-assessment Guide. Penilaian dilakukan terhadap 26 subkategori NIST CSF yang relevan dengan 9 enabler process COBIT 5 terpilih pada tahapan sebelumnya. Penilaian kapabilitas menunjukkan bahwa 19 subkategori berada pada level 0 COBIT 5 PAM dan 7 subkategori berada pada level 1 COBIT 5 PAM. Berdasarkan hal tersebut, dapat disimpulkan bahwa current profile UO ABC berada pada tier 1 NIST CSF yang berarti bahwa proses manajemen risiko organisasi belum terbentuk secara formal.

\section{Conduct risk assessment dan create a target profile}

Pada tahap ini dilakukan penilaian risiko siber terhadap sistem informasi XYZ sekaligus penentuan target profile UO ABC. Dari hasil identifikasi aset, ancaman, dan kerawanan pada tahap sebelumnya, ditemukan 35 risiko mungkin terjadi terhadap sistem informasi XYZ. Selanjutnya risiko-risiko tersebut dinilai menggunakan matriks ISO 27005:2011 yang dapat dilihat pada

TABEL 1 .

TABEL 1

MATRIKS NILAI RISIKO ISO 27005:2011

\begin{tabular}{|c|c|c|c|c|c|c|}
\cline { 2 - 7 } & \multicolumn{1}{c|}{$\begin{array}{c}\text { Kecenderungan skenario } \\
\text { terjadi }\end{array}$} & $\begin{array}{c}\text { Sangat } \\
\text { Rendah (SR) }\end{array}$ & Rendah (R) & Sedang (S) & Tinggi (T) & $\begin{array}{c}\text { Sangat } \\
\text { Tinggi (ST) }\end{array}$ \\
\hline \multirow{4}{*}{$\begin{array}{c}\text { Sampat Rendah (SR) } \\
\text { Bisnis }\end{array}$} & Rendah (R) & 1 & 1 & 2 & 3 & 4 \\
\cline { 2 - 7 } & Sedang (S) & 2 & 3 & 3 & 4 & 5 \\
\cline { 2 - 7 } & Tinggi (T) & 3 & 4 & 5 & 6 & 6 \\
\cline { 2 - 7 } & Sangat Tinggi (ST) & 4 & 5 & 6 & 7 & 8 \\
\hline
\end{tabular}

Penilaian risiko menghasilkan 13 risiko bernilai tinggi dan 22 risiko bernilai sedang. Setelah mengetahui nilai risiko, UO ABC menentukan respon risiko berdasarkan COBIT 4 for Risk yang membagi respon risiko menjadi 4 jenis yaitu menghindari risiko, menerima risiko, membagi risiko dan mitigasi risiko. Hasil nilai respon risiko dapat dilihat pada TABEL 2.

TABEL 2. NILAI DAN RESPON RISIKO

\begin{tabular}{|c|c|c|c|}
\hline No. & $\begin{array}{c}\text { ID } \\
\text { risiko }\end{array}$ & Nilai risiko & $\begin{array}{c}\text { Respon } \\
\text { risiko }\end{array}$ \\
\hline 1. & R1 & Tinggi & Dimitigasi \\
\hline 2. & R2 & Sedang & Dimitigasi \\
\hline 3. & R3 & Tinggi & Dimitigasi \\
\hline 4. & R4 & Tinggi & Dimitigasi \\
\hline 5. & R5 & Tinggi & Dimitigasi \\
\hline 6. & R6 & Tinggi & Dimitigasi \\
\hline 7. & R7 & Sedang & Dimitigasi \\
\hline 8. & R8 & Tinggi & Dimitigasi \\
\hline 9. & R9 & Sedang & Dimitigasi \\
\hline 10. & R10 & Sedang & Dimitigasi \\
\hline 11. & R11 & Sedang & Dimitigasi \\
\hline 12. & R12 & Tinggi & Dimitigasi \\
\hline 13. & R13 & Sedang & Dimitigasi \\
\hline 14. & R14 & Tinggi & Dimitigasi \\
\hline 15. & R15 & Sedang & Ditransfer \\
\hline
\end{tabular}

\begin{tabular}{|c|c|c|c|}
\hline No. & $\begin{array}{c}\text { ID } \\
\text { risiko }\end{array}$ & Nilai risiko & $\begin{array}{c}\text { Respon } \\
\text { risiko }\end{array}$ \\
\hline 16. & R16 & Sedang & Dimitigasi \\
\hline 17. & R17 & Sedang & Dimitigasi \\
\hline 18. & R18 & Sedang & Ditransfer \\
\hline 19. & R19 & Tinggi & Ditransfer \\
\hline 20. & R20 & Tinggi & Dimitigasi \\
\hline 21. & R21 & Sedang & Dimitigasi \\
\hline 22. & R22 & Sedang & Dimitigasi \\
\hline 23. & R23 & Sedang & Dimitigasi \\
\hline 24. & R24 & Tinggi & Dimitigasi \\
\hline 25. & R25 & Sedang & Dimitigasi \\
\hline 26. & R26 & Sedang & Dimitigasi \\
\hline 27. & R27 & Sedang & Ditransfer \\
\hline 28. & R28 & Sedang & Dimitigasi \\
\hline 29. & R29 & Tinggi & Dimitigasi \\
\hline 30. & R30 & Sedang & Dimitigasi \\
\hline 31. & R31 & Sedang & Dimitigasi \\
\hline 32. & R32 & Tinggi & Dimitigasi \\
\hline 33. & R33 & Sedang & Dimitigasi \\
\hline 34. & R34 & Sedang & Dimitigasi \\
\hline 35. & R35 & Sedang & Ditransfer \\
\hline
\end{tabular}

Hasil respon risiko menunjukkan bahwa terdapat 30 risiko akan dimitigasi dan 5 risiko ditransfer kepada pihak ketiga. Berdasarkan hal tersebut, UO ABC kemudian menentukan enabler process COBIT 5 yang akan digunakan untuk memitigasi 
risiko. Setelah enabler process mitigasi terpilih, ditentukan subkategori NIST CSF yang relevan terhadap enabler process tersebut sehingga dapat ditentukan subkategori NIST CSF yang akan diterapkan. Hasil penentuan mitigasi risiko dan subkategori NIST CSF dapat dilihat pada

TABEL 3

TABEL 3.

MITIGASI RISIKO

\begin{tabular}{|c|c|c|c|}
\hline $\begin{array}{c}\text { Generic risk } \\
\text { scenario }\end{array}$ & $\begin{array}{c}\text { Enabler } \\
\text { process COBIT } \\
\mathbf{5} \text { sebagai } \\
\text { mitigasi }\end{array}$ & $\begin{array}{c}\text { Subkategori } \\
\text { NIST CSF } \\
\text { yang akan } \\
\text { diterapkan }\end{array}$ & $\begin{array}{c}\text { Tambahan } \\
\text { proses yang } \\
\text { akan } \\
\text { diterapkan }\end{array}$ \\
\hline \multirow{4}{*}{$\begin{array}{c}\text { Staff } \\
\text { operasional }\end{array}$} & DSS01-01 & - & DSS01-01 \\
\cline { 2 - 4 } & DSS01-04 & $\begin{array}{c}\text { PR.IP-5 } \\
\text { PR.AC-2 } \\
\text { PR.AC-3 }\end{array}$ & - \\
\cline { 2 - 4 } & DSS01-05 & - & DSS01-05 \\
\hline \multirow{4}{*}{$\begin{array}{c}\text { Informasi } \\
\text { Perangkat } \\
\text { lunak }\end{array}$} & DSS01-01 & - & DSS01-01 \\
\cline { 2 - 4 } & DSS01-05 & - & DSS01-05 \\
\cline { 2 - 4 } & BAI06-01 & $\begin{array}{c}\text { PR.DS-1 } \\
\text { BAI06-02 }\end{array}$ & - \\
\cline { 2 - 4 } & BAI06-03 & - & BAI06-02 \\
\cline { 2 - 4 } & BAI06-04 & - & BAI06-03 \\
\hline
\end{tabular}

Berdasarkan Tabel 3, terdapat 7 enabler process terpilih sebagai mitigasi risiko. Namun, hanya 2 enabler process (DSS01-04 dan BAI06-01) yang relevan dengan subkatgori NIST CSF sehingga 5 enabler process lainnya (DSS01-01, DSS01-05, BAI06-02, BAI06-03, BAI06-04) diterapkan sebagai proses tambahan.

Selanjutnya target profile ditentukan terhadap subkategori NIST CSF yang akan diterapkan. Berdasarkan current profile yang telah diketahui, UO ABC menentukan target profile mencapai tier 3 NIST CSF (level 3 COBIT 5 PAM) agar cyber-risk management sistem informasi XYZ dapat dituangkan dalam sebuah kebijakan resmi dan dilaksanakan secara formal.

\section{Determine, analyze, and prioritize}

Pada tahap ini dilakukan analisis gap antara current profile yang telah diketahui dan target profile yang telah ditentukan serta memprioritaskan rencana aksi (program kerja) yang disusun. Hasil analisis gap dapat dilihat pada TABEL 4.

\begin{tabular}{|c|c|c|c|c|c|}
\multicolumn{7}{c}{ TABEL 4. HASIL ANALISIS GAP } \\
\hline No & $\begin{array}{c}\text { ID } \\
\text { Subkategori }\end{array}$ & $\begin{array}{c}\text { Presentase } \\
\text { Cevel } \\
\text { pencapaian } \\
\text { indikator } \\
(\%)\end{array}$ & $\begin{array}{c}\text { Target } \\
\text { level }\end{array}$ & Gap \\
\hline 1. & PR.IP-5 & 0 & 50 & 3 & 3 \\
\hline 2. & PR.AC-2 & 0 & 50 & 3 & 3 \\
\hline 3. & PR.AC-3 & 0 & 50 & 3 & 3 \\
\hline
\end{tabular}

\begin{tabular}{|c|c|c|c|c|c|}
\hline 4. & PR.DS-1 & 0 & 50 & 3 & 3 \\
\hline 5. & PR.IP-3 & 0 & 50 & 3 & 3 \\
\hline
\end{tabular}

Tabel 4. menunjukkan bahwa nilai gap yang didapatkan adalah 3. Hal ini berarti UO ABC perlu meningkatkan kapabilitas subkategori yang akan diterapkan melalui 3 level, yaitu level 0 menuju level 1 , level 1 menuju level 2 , dan level 2 menuju level 3.

Setelah mengetahui nilai gap, selanjutnya menentukan rencana-rencana aksi untuk mengatasi gap tersebut sesuai dengan indikator pada setiap levelnya. Rencana aksi pada level 0 menuju level 1 ditentukan dengan mengacu pada aktivitas COBIT 5 Enabling Process. Rencana aksi pada level 1 menuju level 2 dan level 2 menuju level 3 ditentukan dengan mengacu pada COBIT 5 PAM. Berikut adalah rencana aksi yang telah disusun menjadi program kerja dan telah diprioritaskan.

\section{Rencana aksi level 0 menuju level 1}

Rencana aksi seperti pada Tabel 5. disusun berdasarkan Base Practices (BP) pada setiap enabler process COBIT 5 yang relevan dengan subkategori yang akan diterapkan.

TABEL 5.

RENCANA AKSI LEVEL 0 MENUJU LEVEL 1

\begin{tabular}{|c|c|c|c|}
\hline $\begin{array}{l}\text { Subkategori } \\
\text { NIST CSF } \\
\text { yang akan } \\
\text { diterapkan }\end{array}$ & $\begin{array}{l}\text { Current } \\
\text { profile }\end{array}$ & $\begin{array}{c}\text { Target } \\
\text { profile }\end{array}$ & Rencana aksi \\
\hline PR.IP-5 & 0 & 3 & $\begin{array}{l}\text { Mengidentifikasi } \\
\text { gangguan pada } \\
\text { lingkungan } \\
\text { operasional baik } \\
\text { yang disengaja }\end{array}$ \\
\hline PR.AC-2 & 0 & 3 & $\begin{array}{l}\text { tidak disengaja } \\
(\text { non-malicious }) \\
\text { - Mendokumentasikan } \\
\text { dan melakukan } \\
\text { penguijian terhadap }\end{array}$ \\
\hline PR.AC-3 & 0 & 3 & $\begin{array}{l}\text { prosedur yang } \\
\text { mencakup } \\
\text { peringatan terhadap } \\
\text { gangguan } \\
\text { lingkungan } \\
\text { operasional } \\
\text { - Membandingkan } \\
\text { pengukuran dan } \\
\text { rencana kontingensi } \\
\text { terhadpa hasil } \\
\text { laporan dan } \\
\text { persyaratan } \\
\text { kebijakan secara } \\
\text { tepat waktu saat } \\
\text { ditemukan } \\
\text { ketidakpatuhan } \\
\text { prosedur }\end{array}$ \\
\hline
\end{tabular}




\begin{tabular}{|c|c|c|c|}
\hline $\begin{array}{l}\text { Subkategori } \\
\text { NIST CSF } \\
\text { yang akan } \\
\text { diterapkan }\end{array}$ & $\begin{array}{l}\text { Current } \\
\text { profile }\end{array}$ & $\begin{array}{c}\text { Target } \\
\text { profile }\end{array}$ & Rencana aksi \\
\hline PR.DS-1 & 0 & 3 & $\begin{array}{l}\text { - Membuat } \\
\text { permintaan } \\
\text { perubahan } \\
\text { konfigurasi } \\
\text { dilakukan secara } \\
\text { formal } \\
\text { - Mengkategorikan }\end{array}$ \\
\hline PR.IP-3 & 0 & 3 & $\begin{array}{l}\text { perubahan (seperti } \\
\text { proses bisnis, } \\
\text { infrastruktur, sistem } \\
\text { operasi, jaringan, } \\
\text { sistem aplikasi, } \\
\text { software package) } \\
\text { - Memprioritaskan } \\
\text { semua perubahan } \\
\text { atau konfigurasi } \\
\text { yang diminta } \\
\text { berdasarkan } \\
\text { persyaratan bisnis } \\
\text { dan teknis, sumber } \\
\text { daya yang } \\
\text { diperlukan dan } \\
\text { hukum, peraturan, } \\
\text { serta alasan } \\
\text { kontraktual terhadap } \\
\text { perubahan yang } \\
\text { diminta }\end{array}$ \\
\hline
\end{tabular}

Rencana aksi level 1 menuju level 2

Rencana aksi seperti pada Tabel 6. disusun berdasarkan Generic Practices (GP) dan Generic Work Product (GWP) level 2 pada COBIT 5 PAM.

TABEL 6.

RENCANA AKSI LEVEL 1 MENUJU LEVEL 2

\begin{tabular}{|c|c|c|}
\hline No & Rencana aksi & Hasil \\
\hline \multirow{4}{*}{1.} & $\begin{array}{l}\text { Mengidentifikasi tujuan dan } \\
\text { ruang lingkup proses }\end{array}$ & \multirow{4}{*}{$\begin{array}{c} \\
\\
\\
\\
\text { Dokuemn/pedoma } \\
\text { n yang } \\
\text { menerangkan } \\
\text { ruang lingkup } \\
\text { pelaksanaan proses }\end{array}$} \\
\hline & $\begin{array}{l}\text { Mendefinisikan kewenangan } \\
\text { dan tanggung jawab dalam } \\
\text { melaksanakan proses dengan } \\
\text { mengacu pada RACI chart } \\
\text { COBIT } 5\end{array}$ & \\
\hline & $\begin{array}{l}\text { Menjalin komunikasi yang } \\
\text { baik dengan pihak-pihak yang } \\
\text { terlibat dalam proses dengan } \\
\text { menyusun mekanisme proses } \\
\text { komunikasi }\end{array}$ & \\
\hline & $\begin{array}{l}\text { Mendokumentasikan rincian } \\
\text { kontrol terhadap output } \\
\text { proses dalam dokumen } \\
\text { perencanaan proses atau } \\
\text { Quality plan }\end{array}$ & \\
\hline & $\begin{array}{l}\text { Mengidentifikasi tujuan dan } \\
\text { ruang lingkup proses }\end{array}$ & \multirow{3}{*}{$\begin{array}{c}\text { Dokumen } \\
\text { perencanaan } \\
\text { proses yang } \\
\text { mencakup sasaran } \\
\text { proses yang } \\
\text { dilaksanakan }\end{array}$} \\
\hline & $\begin{array}{l}\text { Merencanakan rincian sasaran } \\
\text { yag akan dicapai pada setiap } \\
\text { proses }\end{array}$ & \\
\hline & $\begin{array}{l}\text { Menyusun standar } \\
\text { kompetensi yang mencakup } \\
\text { definisi pengalaman, } \\
\text { pengetahuan, dan keahlian }\end{array}$ & \\
\hline
\end{tabular}

\begin{tabular}{|l|l|l|}
\hline No & \multicolumn{1}{|c|}{ Rencana aksi } & \multirow{2}{*}{ Hasil } \\
\hline & yang dibutuhkan & \\
\cline { 2 - 2 } & $\begin{array}{l}\text { Mengidentifikasi dan } \\
\text { memastikan ketersediaan } \\
\text { sumberdaya termasuk } \\
\text { informasi yang dibutuhkan } \\
\text { dalam melaksanakan proses }\end{array}$ & \\
\cline { 2 - 2 } & $\begin{array}{l}\text { Menjalin komunikasi yang } \\
\text { baik dengan pihak-pihak yang } \\
\text { terlibat dalam proses }\end{array}$ & \\
\hline
\end{tabular}

\section{Rencana aksi level 2 menuju level 3}

Rencana aksi seperti pada Tabel 7. disusun berdasarkan Generic Practices (GP) dan Generic Work Product (GWP) level 2 pada COBIT 5 PAM.

TABEL 7.

RENCANA AKSI LEVEL 2 MENUJU LEVEL 3

\begin{tabular}{|c|c|c|}
\hline No & Rencana aksi & Hasil \\
\hline 1. & $\begin{array}{l}\text { Mengidentifikasi elemen dasar } \\
\text { yang diperlukan dalam } \\
\text { pembuatan standar proses } \\
\text { meliputi rincian sasaran } \\
\text { proses, standar minimum } \\
\text { kinerja proses, SOP, dan } \\
\text { persyaratan laporan } \\
\text { monitoring } \\
\text { Menentukan pembagian tugas } \\
\text { dan kompetensi yang } \\
\text { dibutuhkan dalam setiap } \\
\text { proses dan mencantumkannya } \\
\text { dalam standar proses yang } \\
\text { dibuat } \\
\text { Mengidentifikasi kebutuhan } \\
\text { infrastruktur (fasilitas, tools, } \\
\text { metode dll) serta lingkungan } \\
\text { implementasi proses dan } \\
\text { mencantumkannya dalam } \\
\text { standar proses } \\
\text { Menentukan metode evaluasi } \\
\text { terhadap kesesuaian standar } \\
\text { proses yang dibuat (audit } \\
\text { internal atau management } \\
\text { review) } \\
\text { Menentukan metode/atribut } \\
\text { pengukuran yang dapat } \\
\text { dilakukan untuk memastikan } \\
\text { apakah proses yang diterapkan } \\
\text { sesuai dengan standar proses } \\
\text { yang dibuat } \\
\text { Mengkomunikasikan } \\
\text { kewenangan dan tanggung } \\
\text { jawab yang telah disusun } \\
\text { dalam standar proses kepada } \\
\text { stakeholder terkait }\end{array}$ & $\begin{array}{c}\text { Dokumen standar } \\
\text { dan kebijakan } \\
\text { pelaksanaan } \\
\text { proses }\end{array}$ \\
\hline 2. & $\begin{array}{l}\text { Memastikan bahwa standar } \\
\text { kompetensi untuk } \\
\text { implementasi proses yang } \\
\text { dicantumkan dalam standar } \\
\text { proses ditentukan dengan tepat }\end{array}$ & $\begin{array}{l}\text { Dokumen yang } \\
\text { menerangkan } \\
\text { ruang lingkup } \\
\text { pelaksasnaan } \\
\text { proses }\end{array}$ \\
\hline
\end{tabular}

\section{Kesimpulan}


Berdasarkan penelitian yang telah dilakukan, dapat disimpulkan bahwa current profile UO ABC mencapai tier 1 (level 0 dan 1 COBIT 5 PAM) NIST CSF yang berarti, proses manajemen risiko organisasi belum terbentuk secara formal. Setelah diketahui bahwa UO ABC memiliki 13 risiko tinggi dan 12 risiko sedang yang mungkin terjadi pada sistem informasi XYZ, UO ABC menentukan 5 subkategori NIST CSF akan diterapkan sebagai mitigasi risiko dengan 5 enabler process COBIT 5 sebagai proses tambahan. Penerapan subkategori tersebut ditargetkan untuk mencapai tier 3 NIST CSF agar organisasi dapat menuangkan proses cyber-risk management sistem informasi XYZ dalam sebuah kebijakan resmi sehingga prosesnya dapat dilakukan secara formal.

Rencana aksi yang dihasilkan untuk menuju tier 3 disusun sesuai dengan indikator pencapaian proses pada setiap level. Secara umum pada level 0 dan 1 (tier 1) UO ABC akan mencapai outcomes proses yang diimplementasikan. Pada level 2 (tier 2) UO ABC akan mencapai kondisi bahwa proses disetujui untuk diterapkan namun belum memiliki kebijakan yang mengaturnya. Pada level 3 UO ABC akan mencapai kondisi bahwa organisasi memiliki kebijakan yang mengatur bagaimana proses diimplementasi.

\section{Referensi}

Jurnal

[2] Y. Chen, P. P. Chong, and B. Zhang, "Cyber security management and e-government," vol. 1, no. 3, pp. 316-327, 2004.

[4] M. J. Hutchins, R. Bhinge, M. K. Micali, S. L. Robinson, J. W. Sutherland, and D. Dornfeld, "Framework for Identifying Cybersecurity Risks in Manufacturing," Procedia Manuf., vol. 1, pp. 47-63, 2015.

[5] I. Rahmawati, "Analisis Manajemen Risiko Ancaman Kejahatan Siber (Cyber Crime) Dalam Peningkatan Cyber Defense," J. Pertahanan dan Bela Negara, vol. 7, no. 2, pp. 51-66, 2017.

Publikasi elektronik atau informasi dari internet

[8] Kominfo, "Tren Serangan Siber Nasional
2016 dan Prediksi 2017," 2017.

https://www.owasp.org/images/4/47/IwanOWASP-Cyber-Security-Trends-2017.pdf

[12] F. Wamala, ITU National Cybersecurity Strategy Guide. 2011.

http://www.itu.int/ITU-

$\mathrm{D} /$ cyb/cybersecurity/docs/ITUNationalCyber securityStrategyGuide.pdf

[13] NIST, "Framework for Improving Critical Infrastructure Cybersecurity Version 1.0," United State, 2014.

https:/www.nist.gov/document-3766

Buku

[1] A. Refsdal, B. Solhaug, and K. Stolen, CyberRisk Management. 2015.

[14] ISACA, COBIT 5 Enabling Processes. 2012.

[15] ISACA, Process Assessment Model (PAM): Using COBIT ® 5.2013.

[16] ISACA, Self-assessment Guide: Using COBIT ${ }^{\circledR}$ 5. Canada, 2013.

[17] ISACA, Using COBIT 5 for Risk Management, vol. 4, no. October. 2013.

[18] ISACA, Implementing The NIST Cybersecurity Framework. 2014.

Tugas Akhir

[3] C. W. Hardani, Analisis Risiko Flight Clearance Information System Menggunaka Risk Scenario COBIT 5 for Risk dan NIST SP 800-30 Revisi 1. 2016.

Paper dan Laporan

[6] R. Von Solms and J. Van Niekerk, "From information security to cyber security," Comput. Secur., pp. 2-7, 2013.

\section{Data Spesial}

[7] Peraturan internal. 2014, pp. 1-64.

[9] Peraturan internal. 2014, pp. 1-250.

[10] Peraturan internal. 2011, pp. 4-19.

[11] Laporan internal, "Sistem informasi XYZ" 2017. 